\title{
The Role Of Sustainable Ceramic Art In Achieving Development
}

\author{
Prof . Abeer Abdallah Shapaan Gohar \\ Professor of Ceramics - Faculty of Specific Education - Menoufia University
}

\section{Abstract:}

The artist is considered a mirror of his age reflecting the ideas and visions after their overlap with his conscience and purification of the impurities of reality to achieve the equation of right and good, and then re-put on the community loaded with aesthetic content expands their vision and raise the general taste, and therefore the data of the ocean around the artist from the visual and vocabulary and materials, The artist travels in his imagination and works with his expertise in proportion to each element and the corresponding technologies to achieve a special and unique artistic work related to the idea of sustainability by upcycling of some elements in aesthetic formulations. 


\title{
The Role Of Sustainable Ceramic Art In Achieving Development
}

\author{
Prof . Abeer Abdallah Shapaan Gohar \\ Professor of Ceramics - Faculty of Specific Education - Menoufia University
}

\section{introduction:}

The artist is considered a mirror of his age reflecting the ideas and visions after their overlap with his conscience and purification of the impurities of reality to achieve the equation of right and good, and then re-put on the community loaded with aesthetic content expands their vision and raise the general taste, and therefore the data of the ocean around the artist from the visual and vocabulary and materials, The artist travels in his imagination and works with his expertise in proportion to each element and the corresponding technologies to achieve a special and unique artistic work related to the idea of sustainability by upcycling of some elements in aesthetic formulations.

\section{The concept of sustainable development:}

Sustainable development is at the intersection of the environment, the economy and society, so governments have to work to make the world's population more aware and concerned about the environment and related problems, so that they have the knowledge, the skills, the means and the commitment to act as individuals or groups, in order to find solutions to problems. The real-time and prevention of new problems "Belgrade's 1976 declaration, we have to care to keep the globe after we leave it with sufficient resources to respond to the needs of future generations

Development is the product of man's work on adapting the elements of the environment and transforming them into riches, that is, meeting the needs of society, this transformation depends on the effort of the human being the scientific knowledge and the use of tools and technical means, and development if not take into account the environmental balances and resources available with the requirements and the Continuity leads to a change in the environment that threatens its innate equilibrium, and reaches the degree of damage if the ability of the environmental instinct exceeds the probability and its ability to regain balance and heal cracks. Hence, the importance of sustainable development has emerged as a new concept 
Sustainable development is the process of developing land, cities and communities as well as business, provided that it meets the needs of the present without compromising the ability of future generations to meet their needs. The world is faced with the seriousness of environmental degradation, which must be overcome without abandoning the needs of economic development as well as equality and social justice

\section{Sustainable art:}

Sustainable art is an art that is consistent with the basic principles of sustainability, encompassing the environment, social justice, nonviolence and popular democracy. Sustainable art can be understood as an art that is produced taking into account the broader impact of the work and its reception in relation to its environment ( Social, economic, historical and cultural)

The roots of sustainable art can be traced back to conceptual art in the late 1960s and early 1970s, where Sol-Sollewitt is known as "an art that incorporates intellectual processes and is liberated from the artist's craftsmanship, where the idea of the artistic work itself becomes the creative process, such as the philosophy defined by Controversy and questioning, resulting in the use of visual perception in harmony with various other senses

Ceramics is one of the most influential environmental-related arts that has been touched by artists and potters, including all stages of the production of ceramic work from fuels, alternative technologies for energy-saving methods, sustainable ways to collect and use clay, and ways to deal with waste and conserve water to reduce The environmental effects of ceramic art .

\section{Upcycling in art :}

The tradition of reusing found objects (objet trouvé) in mainstream art came of age sporadically through the 20th century, although it has long been a means of production in folk. Simon Rodia's Watts Towers (1921-1954) in Los Angeles exemplifies upcycling of scrap metal, pottery and broken glass on a grand scale; it consists of 17 structures, the tallest reaching over 30 meters into the Watts skyline. 

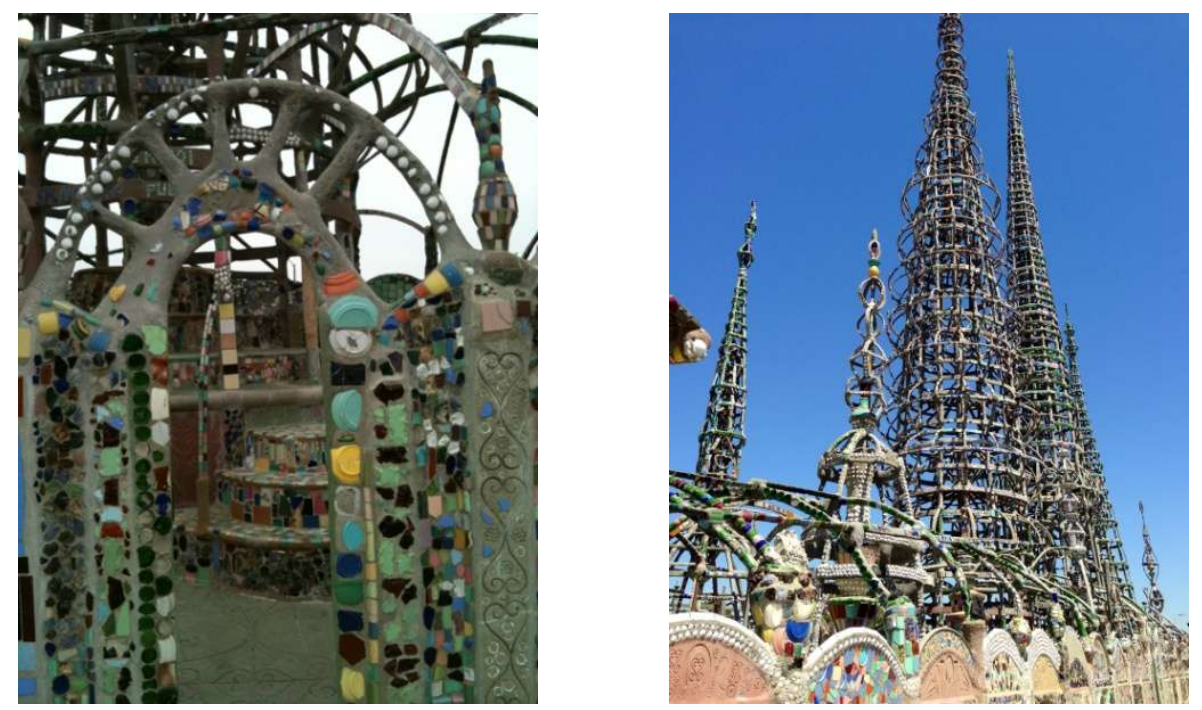

Intellectually, upcycling bears some resemblance to the ready-made art of Marcel Duchamp and the Dadaists. Duchamp's "Bicycle Wheel" (1913), a front wheel and fork attached to a common stool, is among the earliest of these works, while "Fountain" (1917), a common urinal purchased at a hardware store, is arguably his best-known work. Pablo Picasso's "Bull's Head" (1942), a sculpture made from a discarded bicycle saddle and handlebars, is the Spanish painter's sly nod to the Dadaists.
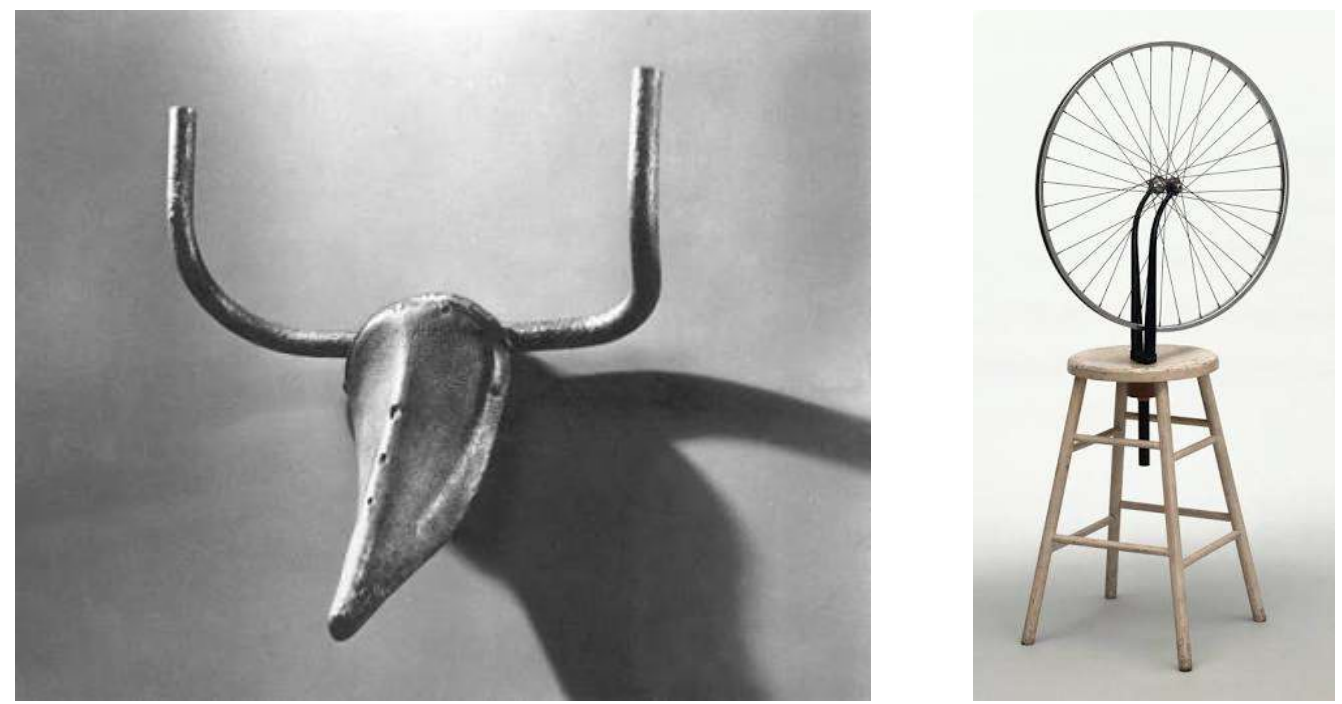
Throughout the mid-century the artist Joseph Cornell fabricated collages and boxed assemblage works from old books, found objects and ephemera. Robert Rauschenberg collected trash and disused objects, first in Morocco and later on the streets of New York, to incorporate into his art works.
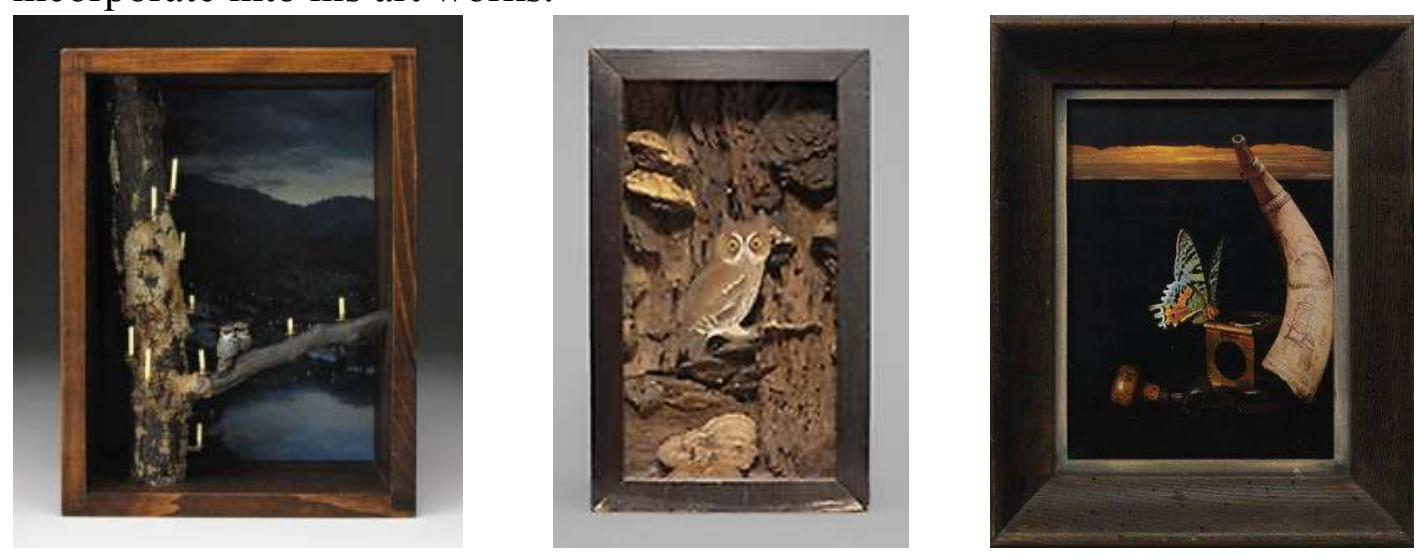

The idea of consciously raising the inherent value of recycled objects as a political statement, however, rather than presenting recycled objects as a reflection or outcome from the means of production, is largely a late 20th century concept,
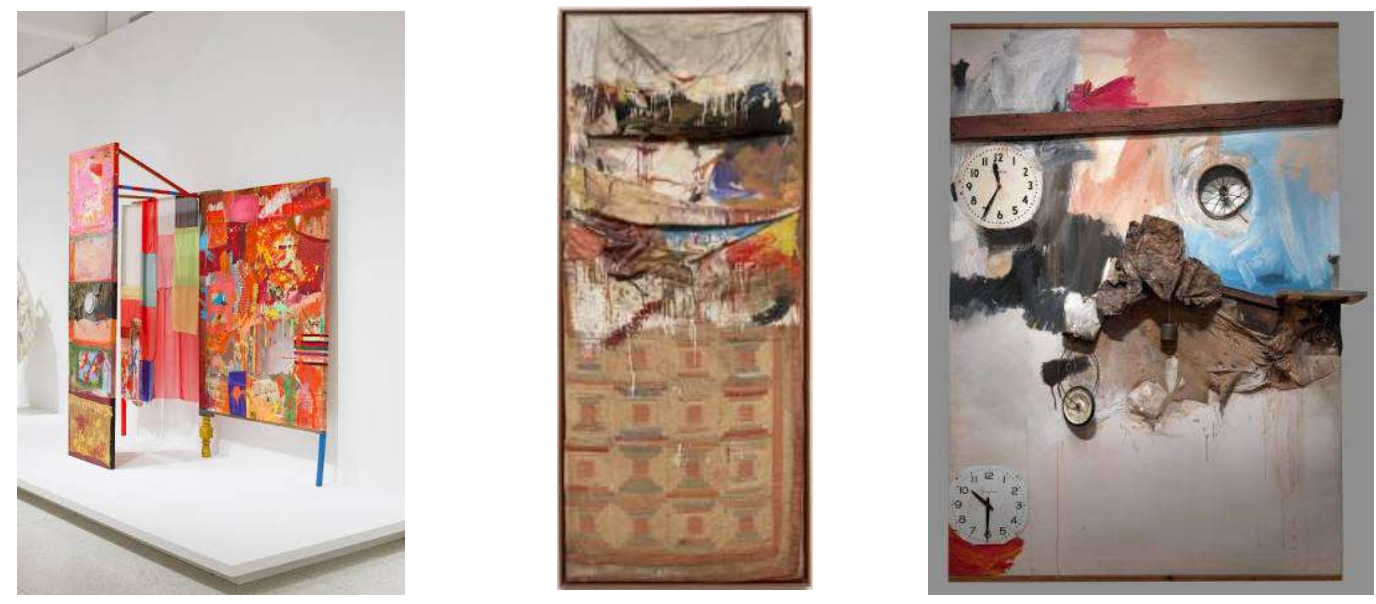

Jeff Wassmann, an American artist who has lived in Australia for the past 25 years, uses items found on beaches and junk stores in his travels to create the early Modern works of a fictional German relative, Johann Dieter Wassmann (1841-1898). In "Vorwarts (Go Forward)" (pictured), Wassmann uses four simple objects to depict a vision of 
modern man on the precarious eave of the 20th century: an early optometry chart as background, a clock spring as eye, a 19th-century Chinese bone opium spoon from the Australian gold fields as nose and an upper set of dentures found on an Australian beach as mouth. Wassmann is unusual among artists in that he does not sell his work, rather they are presented as gifts; by not allowing these works to reenter the consumer cycle, he averts the commodification of his end product.

Romuald Hazoumé an artist from the West African Bénin, was heralded in 2007 for his use of discarded plastic gasoline and fuel canisters to resemble traditional African masks at Documenta 12 in Kassel, Germany. Hazoumé has said of these works, "I send back to the West that which belongs to them, that is to say, the refuse of consumer society that invades us every day.
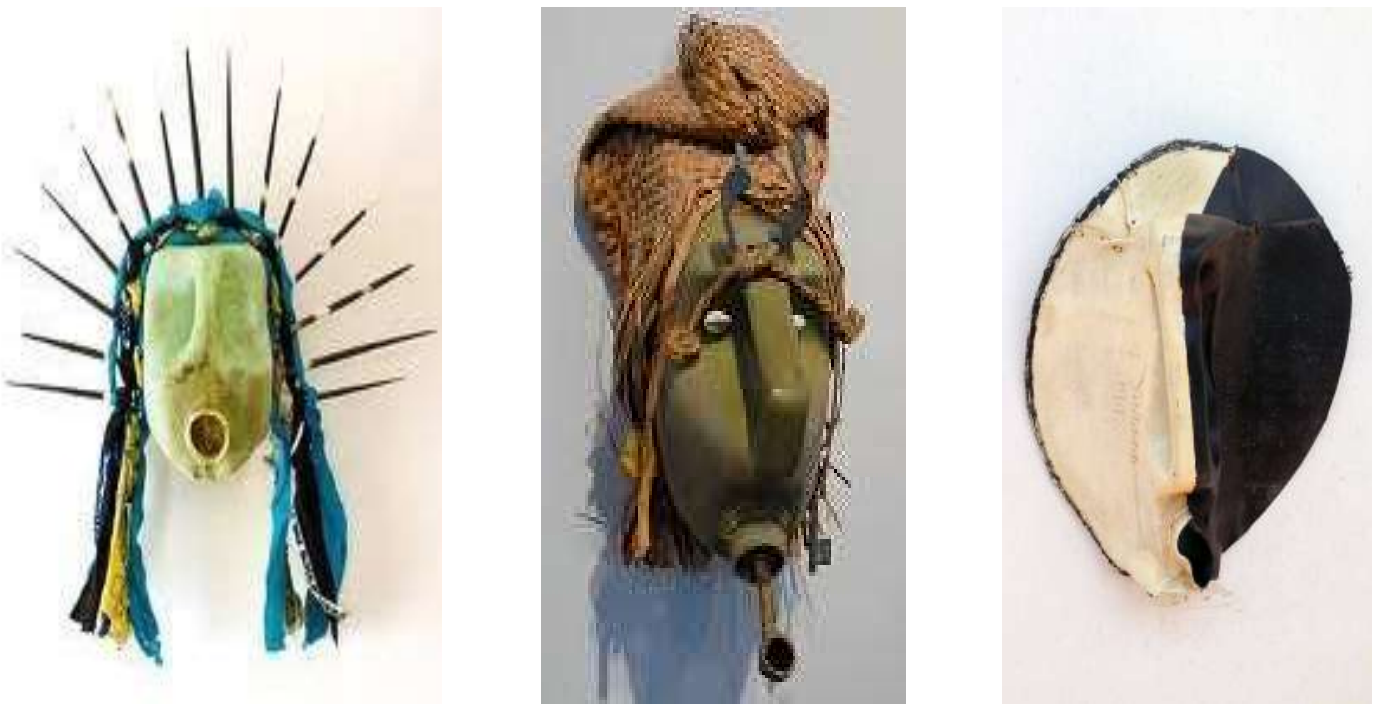

Max Zorn is a Dutch tape artist who creates artwork from ordinary brown packaging tape and hangs pieces on street lamps as a new form of street art at night. By adding and subtracting layers of tape on acrylic glass with a surgical scalpel, the artwork can only be visible when light is placed behind it, mimicking the effects similar to stained glass window methods. His technique with pioneering upcycling with street art has been featured at Frei-Cycle 2013, the first design fair for recycling and upcycling in Freiburg, Germany. 


\section{Skills Of Sustainable Ceramic Artist :}

1- Hand Skill: It is a characteristic of the literal artist and requires the practice of activities that require the synergy of visual mobility of one or two hands, and the practice of ceramic clay formation and adaptation techniques and the development of new methods to overcome some of the technical problems associated with recycling for some of the most important features of the creative best character of the Ceramic Artist

2- Academic perseverance: determined to perform artistic or creative performance, a self-based desire to carry out a certain plan, is illustrated by the constant experimentation with the raw waste Matt Ceramic Production of porcelain production in various technical methods and redraft of plastic vocabulary in the light of the concept of upcycling to achieve the artistic and aesthetic values of the artistic work

3- Ease of Perception: This terminology symbolizes the ease and readiness that the potter responds to and retains expertise in particular visual experience and cosmetic skills, as well as the ability of potter to classify data The residue of ores, production and how to upcycle, it also means the ease and speed of realizing the technical relations of the vocabulary and how it employs it to get out of art .

4- Aesthetic Intelligence: This feature symbolizes the relationship between general intelligence and the ability to perform creative artistic performance, from the perspective of Meyer, innovative work results from a clever organization of the knowledge of the creative person .

5- Creative imagination: It is easy to regulate the vocabulary in aesthetic concepts and formations, which are placed in a building or composition that is an appropriate expression and in clear ways to others, and this building or composition has its aesthetic status when its elements are regulated according to the principles and aesthetic rules of sustainable ceramic

6- Governance is the extent to which an individual can rule on any technical work or design what is based on the foundations of the smart aesthetic organization of the ceramic work, which is also the ability to recognize the aesthetic values of the ceramic works associated with the idea of sustainability by upcycle .

\section{Ceramic artists and upcycling :}

The modern era has undergone changes since the First World War, with a revolution in art characterized by a wide variety of style and performance, and contemporary artists are still looking into the tradition of the new era, reflecting its culture and faithfully expressing 
it, and as a result, the Ceramic artist was obliged to be knowledgeable Technical and scientific ability of the new artistic directions and the realization of the aesthetic, philosophical and expressive meanings behind it

The modern ceramic artist has moved away from cloning and took care of the one piece art, the artwork with the single copy has its own value derived from its uniqueness and the single piece of ceramic is taken into account aesthetic aspects and focus on the technique and modulation methods,

It also includes the concepts and expressive values and the ceramic art has become a pure art free from the constraints imposed by the functional aspects and interested in the achievement of aesthetic pleasure in the light of contemporary philosophical concepts and trends and issues of contemporary society, yet the transformation in the look of some ceramic artist for the role of artistic work and its relevance to current concepts and life issues, including attempts by the international community to reduce the amount of waste polluting the environment and the quantities of waste generated by industry in an effort to conserve and sustain natural resources For future generations, highlighting the role of upcycle and its association with ceramic art .

\section{Li Xiaofeng :}

Considered one of the most original artists in China, Li Xiaofeng (b. 1965) is known for his unique use of porcelain shards. Li makes wearable porcelain costume and installation from ceramic shards coming from the Song, Ming, Yuan and Qing dynasties, which are sewn together on a leather undergarment.
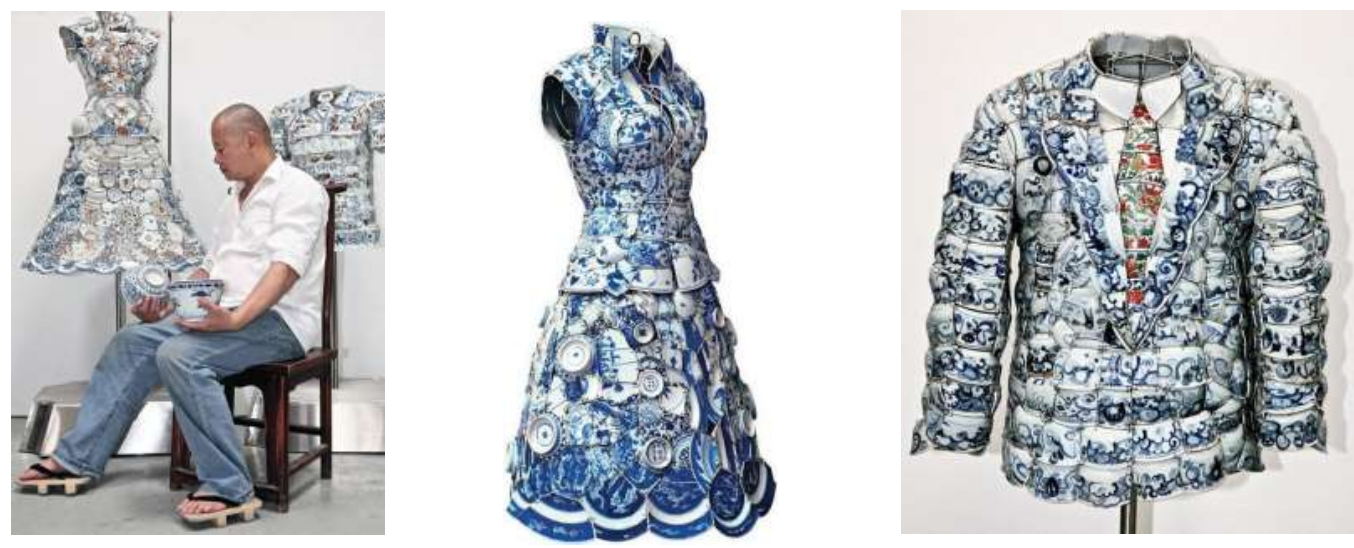


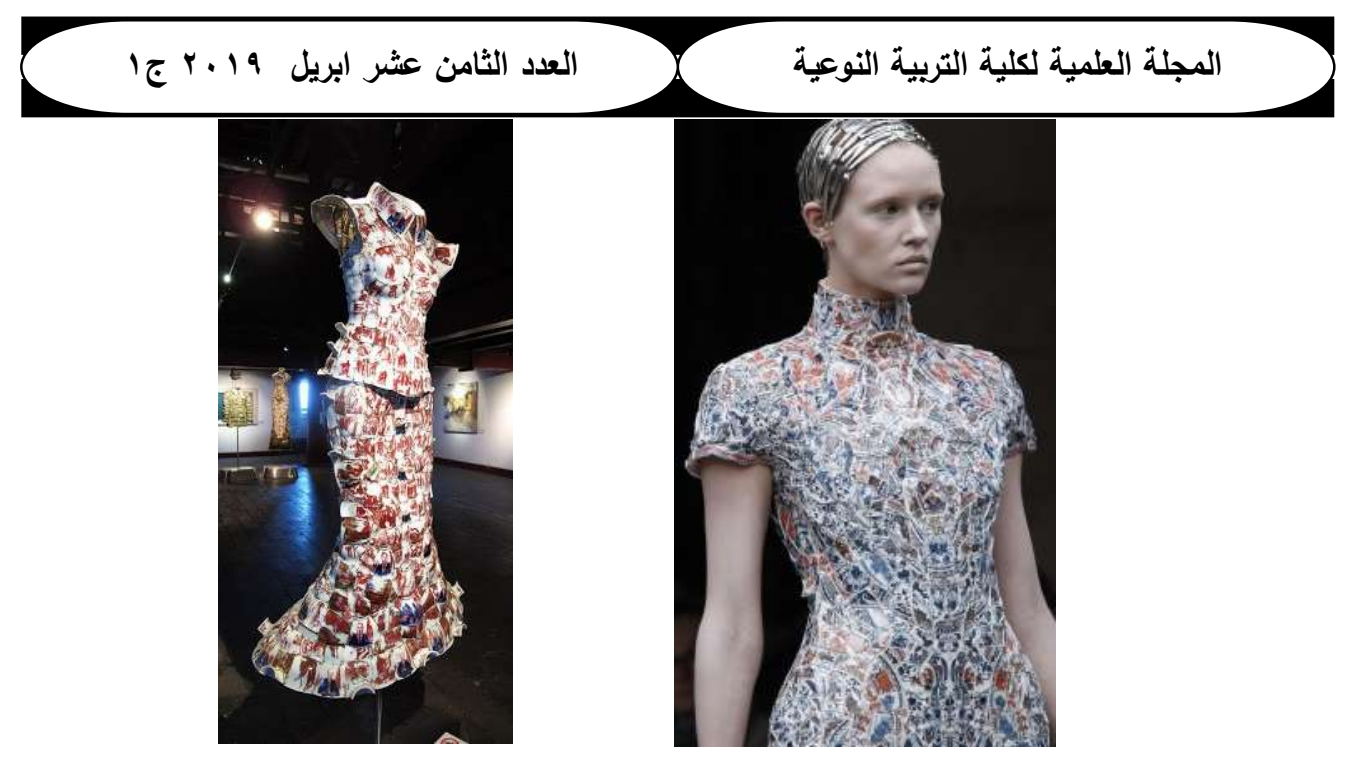

\section{Robert Harrison :}

in his book of sustainable ceramic said that ceramic one of the arts associated with the environment in terms of influence and impact is choosing the raw, its composition and burning are at a stage where it takes into account to be environmentally friendly in seeking access to green art (clean and Dame, Harrison has been interested in collecting thousands of porcelain pieces and fragments from many places and trying to recycle them for the best of creating architectural parts such as large mineral brackets and participating in the art exhibition in 2015
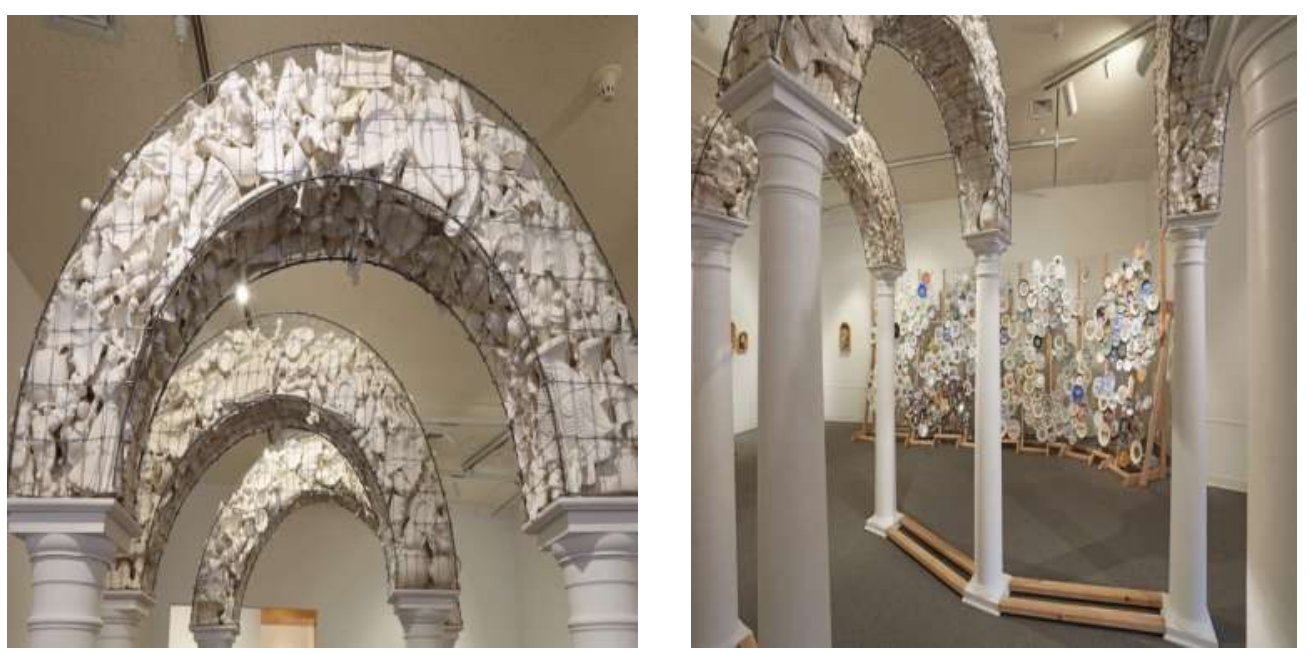


\section{دور فن الخزف المستدام في تحقيق التنمية \\ أ.د عبير عبدالله شعبان}

الملخص

يعتبر الفنان مرآه لعصره تعكس الافكار والرؤى بعد تداخلها مع وجدانه وتتقيتها من

شوائب الواقع لتحقيق معادلة الحق والخير ، ثم يعيد طرحها علي المجتمع محملة بمضامين جمالية تتسع معها رؤيتهم وترثقي بالذوق العام ، وعلي ذلك تعتبر معطيات المحيط حول الفنان من مرئيات ومفردات تشكيلية ومواد خام ومصنعة مجالاً رحباً يجول فيه الفنان بخيالاته ويعمل فيه بخبراته بما يتتاسب وكل عنصر وما تتوافق معه التقنيات وصولا لعمل فني خاص وخالص يرتبط بفكرة الاستدامة عن طريق اعادة التدوير للأفضل لبعض العناصر في صياغات تتكيلية جمالية . 